\title{
Technological Features of Meta-Subject Expertise Development in Mathematical Education of Secondary School Students of $5^{\text {th }}$ Grades
}

\author{
Rail M. Asadullin ${ }^{1}$, Marina V. Naumova ${ }^{1 *}$, Vera K. Vlasova ${ }^{2}$, Daniya Z. Akhmetova ${ }^{3}$, \\ Svetlana P. Zubova ${ }^{4}$ \\ ${ }^{1}$ Bashkir State Pedagogical University named after M. Akmullah, Ufa, RUSSIA \\ ${ }^{2}$ Kazan (Volga region) Federal University, Kazan, RUSSIA \\ ${ }^{3}$ Kazan Innovative University named after V.G. Timiryasov, Kazan, RUSSIA \\ ${ }^{4}$ Samara State University of Social Sciences and Education, Samara, RUSSIA
}

Received 17 March 2018 - Revised 3 August 2018 - Accepted 21 August 2018

\begin{abstract}
The relevance of the research lies in the necessity to cultivate the development of the person who can adapt to conditions of education, response proportionally to changes in the structure and content of educational processes and always be ready for continuous self-development. This research can be performed even at a school educational process using the traditional curriculum and subjects, namely mathematics, in case an educational process is aimed at the achievement of high results in the matter, personal and meta-subject aspects. The modern educational process during mathematics lessons according to the federal standard regulations and recommendations from the Concept of mathematical education development of the Russian Federation has to be aimed at the development of meta-subject skills. This can be provided in case if the meta-subject expertise development technology is applied which helps boost a student's potential of acquiring meta-subject, personal and subject educational results supplied that mathematics stayed integral and connected with other educational spheres. The article contains reasonable details of the technology, such as the structure and aims of educational processes among pupils for further development of their meta-subject expertise in mathematics. Also, a sophisticated diagnostic programme of tracing of meta-subject learning results dynamics in mathematics among secondary school students of $5^{\text {th }}$ grades aged $11-12$ years is introduced. The results of the conducted research indicate that the development of the meta-subject expertise by computation among pupils of the secondary school makes it possible to arrange a more effective educational process to achieve high metasubject results.
\end{abstract}

Keywords: technology, mathematics in secondary school, the structure of a mathematical education course, subject to an educational process, diagnostic programme

\section{INTRODUCTION}

\section{Relevance of the Research}

In the Concept of mathematical education development of the Russian Federation the necessity to modernize content of the existing educational programmes to elaborate and implement methodological approaches and

(C) 2018 by the authors; licensee Modestum Ltd., UK. This article is an open access article distributed under the terms and conditions of the Creative Commons Attribution License (http://creativecommons.org/licenses/by/4.0/). $\square$ rail_53@mail.ru $\square$ marina.naumova.85@bk.ru (*Correspondence) $\square$ v2ko@mail.ru $\square$ ahmetova@ieml.ru 


\section{Contribution of this paper to the literature}

- A new technology of meta-subject expertise development among pupils of the secondary school is introduced which consists of the aim, tasks, principles, stages, methods, educational instruments for pupils of $5^{\text {th }}$ grades. The technology is aimed primarily at pupil's personal development.

- The organizational and pedagogical conditions of the new technology implementation aimed at metasubject expertise development are defined. They are comprehension, integrity, systematical approach and control.

- In the practical work with pupils along with mathematical tasks the multidimensional planning technologies of V.E. Steinberg are widely used, as well as the universal didactic units of P.M. Erdniyev. The latter was earlier excluded from the traditional methodology of the mathematical education. multidimensional planning.

private courses is stated, as well as to create and integrate special conditions for personal development and popularization of mathematical knowledge (The concept of development of mathematical education in the Russian Federation, 2013). Moreover, the new federal state standards define the essential criteria for pupils' assessment results available for achievement in a standardized way.

According to Asadullin (2009), the theoretical and methodological approaches in pedagogy lead to a tendency of the educational process change and enhancement of pupils' ability to analyze educational results. All these aspects have to be taken into account in order to achieve the common goal in the system of education on the example in the mathematical sphere, i.e., development of a person on the subject, personal and meta-subject levels. Besides, the theoretical and methodological approaches to the mathematical education of pupils in modern pedagogy imply provision of the conditions for continuous self-development of the person who is eager to achieve success and able to define tasks and find solutions not only in educational processes but also in everyday life (Gorev et al., 2017; Khuziakhmetov \& Sytina, 2016). Many modern researchers confirm that this can lead to further school graduates' adaptation to their postgraduate education and professional activities (Cohen \& Smerdon, 2009; Sopegina, Chapaev \& Simonova, 2016; Yakushev, 2013).

The necessity to enhance achievement of educational results on the subject, personal and meta-subject levels is supported by the documents mentioned above, i.e., it is officially confirmed. Nevertheless, it has to be noted that there are still no appropriate, informative and accessible technologies for meta-subject expertise development. Moreover, there are various methods of the meta-object diagnostics among pupils at schools, models, and schemes not connected with each other and interfering comprehension of the organization of the educational process in any sphere, including mathematics.

Teachers and pedagogical staff are simply confused choosing a diagnostic methodology, method, test or questionnaire which could assess meta-subject skills without bias and define advantages and drawbacks of the educational process the organization aimed at the performance of the necessary activities, curriculum, and education strategy. Besides, an instructional approach can be hardly chosen due to various theoretical and methodological recommendations regarding implementation of private diagnostic methods.

The relevance of the research also lies in the fact that the elaborated meta-subject expertise technology can greatly help achieve necessary meta-subject results. But still, there are arguments on the content of meta-subject level expertise (Delamare \& Winterton, 2007; Testov, 2014). In the pedagogical society, there is a great difficulty in implementation of such an expertise development strategy (Guruzhapov, 2012), especially concerning the approaches to such terms as 'competence' and 'expertise' (Chilingaryan \& Gorbatenko, 2014). On the other hand, the development of subject competences is impossible without the development of the meta-subject ones, as, for instance, if we deal with figures, then the acquired knowledge will likely be useful on geography lessons as well as in everyday life. Thus, meta-subject expertise is strongly interconnected with the learning of other subjects and has to be obtained purposefully (Konovko, 2012; Semenov \& Atasyan, 2014; Verbitskiy \& Ermakova, 2009).

\section{The Aims and Tasks of the Research}

The aim of the article is the elaboration of the meta-subject expertise technology with the help of mathematical instruments during the continuous personal development of a pupil who is able to adapt to an education process, respond proportionally to changes in the structure and content of education processes and be ready for continuous self-development. The main tasks were as follows: to define the structure of pupils' meta-subject expertise, to elaborate a new diagnostic programme, instruments, and criteria for assessment; to test the conceptual, technological and the organizational conditions in the educational process among pupils in the secondary school; to make conclusions regarding efficiency of the proposed requirements for meta-subject expertise development. 


\section{Review of the Resources}

The issue of the organization of meta-subject expertise development has been studied by many scientists. Researchers considered various aspects and approaches to the features of meta-subject expertise development. Namely, researchers tried to find the organizational conditions enhancing meta-subject expertise development (Gorev et al., 2017). The necessity of effective the organization of a meta-subject expertise development process was strongly connected with further pupils' adaptation not only to their education at universities but to their professional activity in the future (Cohen \& Smerdon, 2009; Sopegina, Chapaev \& Simonova, 2016; Yakushev, 2013). On the other hand, the researchers tried to define the elements and features of meta-subject expertise considering such closely connected terms as 'expertise' and 'competence' (Chilingaryan \& Gorbatenko, 2014; Delamare \& Winterton, 2007; Guruzhapov, 2012; Testov, 2014).

The existing scientific attitudes concerning the organization of meta-subject expertise development have much in common in terms of interconnection of a 'meta-subject' and a 'subject'. In this view forms, instruments and methods of the technology can be implemented in greater degree not only in mathematical education but, for example, in geography or other subjects (Semenov \& Atasyan, 2014; Konovko, 2012; Verbitskiy \& Ermakova, 2009). Moreover, currently, the researchers proposing multidimensional technologies (primarily, author ones) in methodology are quite significant and aimed at the development of meta-subject skills (Erdniyev, 2001; Illushin et al., 2005; Steinberg \& Khuziakhmetov, 2016).

The utmost contribution to development of the meta-subject expertise research and the technology elaboration was conducted by the scientists following the subject-oriented approach, such as Asadullin (2009), Lerner (2003), Novikov (2010), Kraevskiy and Khutorskoy (2003); the adherents of the psychological and pedagogical activity approach Vygotskiy (1999), Leontiev (1956), Rubinstein (1913); Khutorskoy and Kraevskiy (2008), Khutorskoy (2003), Lebedev (2004), Osgood and Tannenbaum (1995), Gorev et al. (2017), Gorev and Masalimova (2017), Gein and Nekrasov, (2013), Masalimova (2017), who considered the concept of the fundamental educational units.

In the different studies, the issue of the organization of meta-subject expertise technology development is connected with such main tasks as integral and all-around pupil's development, preparing to future adult life in the academic or professional sphere (Sanderse, Walker, \& Jones, 2015). These tasks can be achieved, according to the scientists, implementing reading strategies and strategies for obtaining necessary information which is closely connected with meta-competencies (Carr \& Borkowski, 1989). Meta-competencies formation is considered as a transitive stage in pupils' development which prepares them for their future social life (Sneed et al., 1994).

Among the researchers, great contribution to the issue of meta-subject expertise development can be called those who take into account self-control and self-assessment as the constituents of the meta-subject expertise level (Brock et al., 2014; Quail \& Smyth, 2014). Besides, obtaining the so-called 'meta' knowledge is connected both with mental operations and pupils' own strategies while performing tasks. Among the strategies integration, metamemory and control can be called (Hu et al., 2018; Miller, 1994). It has to be noted that pupils develop skills of different activities on the 'meta' level from the early school age (Praet \& Desoete, 2014).

The researchers regarding meta-analysis are quite relevant and in demand. This is not only a method of obtaining the key information but the universal approach which can be implemented in any professional, educational and scientific spheres (Borenstein et al., 2009, 2010). Moreover, it implies that an ordinary conversation between pupils is performed on the meta-subject level. From this point of view, those researchers where decisionmaking during a meta-conversation, where defining of our own emotional state and associations become an object of investigation are quite significant (Duan et al., 2018; Köymen \& Tomasello, 2018; Voltmer \& Salisch, 2017).

\section{MATERIALS AND METHODS}

\section{The Methods of the Research}

The following methods were used for elaboration of the meta-subject expertise development technology: analysis of the psychological, pedagogical, mathematical and methodological resources on the subject of the article, analysis of the educational process results, analysis and accumulation of the teachers' and own professional experience in teaching of mathematics in the secondary school, prognosis, systematization and collection of the facts and conceptions, modelling, methods of the expert assessment, planning, elaboration and implementation of the teaching materials in the mathematical education, the diagnostic methodologies, analysis of the education activity results, a pedagogical experiment.

\section{The Research Experimental Basis}

Approbation, generalization, and implementation of the results of the article are carried out in the secondary school. The elaborated technology of meta-subject expertise development had been implemented using the 
materials provided by the originators (Khuziakhmetova \& Naumova, 2016); the technique is applied since 2014 in the educational establishment - MBGEI ‘Gymnasium № 64' of Ufa and 'Gymnasium № 6' of Kazan which provides teaching of the programmes according to the federal standards of education in the secondary (full) education. The participants of the technology implementation were the pupils of $5^{\text {th }}$ grades aged 11-12 years. The $5^{\text {th }}$ graders were divided into two groups of pupils (total - 59 people: the control group - 30, the experimental one - 29). The pupils of the experimental group took part in the experiment in 2014/2015. They studied in the gymnasium from the first grade and during the education process in $5^{\text {th }}$ grade their meta-subject expertise in mathematics was developed with help of multidimensional planning of V.E. Steinberg and universal didactic units of Erdniyev (Erdniyev, 2001; Steinberg \& Khuziakhmetov, 2016). The control group was used as a baseline to compare and assess the effect. Implementation in several stages started in 2014.

\section{The Stages of the Research}

The Research Is Conducted in Several Stages

At the first stage, the state of the relevant issue in the theoretical and practical aspect of the mathematical education at secondary schools was investigated. To achieve the aim of the first stage the psychological, pedagogical, mathematical and methodological literature concerning the issue was analyzed and considered, as well as observation and analysis of the teachers' experience in mathematics was conducted in order to find out a meta-subjective potential of mathematics and activities enhancing meta-subject expertise with the help of mathematical instruments increasing pupils' knowledge in mathematics and achieving high meta-subject results.

The second stage included studying of the methodological approaches to implementation of the meta-subject expertise development technology in the mathematical education with the help of various meta-subject-oriented the organizational activities following the strategy of the personal pupil's development who is able to adapt to many educational conditions and respond proportionally to changes in the structure and content of educational processes. The content selection of mathematical lessons was carried out. Implementation of the meta-subject expertise development technology was and still is discussed not only by the author of the article and pupils themselves but also by the teachers of other subjects implementing the technology in their educational spheres. Moreover, many reports at conferences on different levels were conducted which lead to consequent enhancement of the proposed technology and ways of its implementation in the mathematical education of pupils.

The third stage included the qualitative and quantitative analysis of meta-subject expertise development technology implementation, accumulation of the results of the research, formulation of the conclusions, clarification of experimental findings, generalization, systematization and explanation of the gained effects implemented in the secondary educational establishments; scientific and methodological recommendations for meta-subjects expertise development in educational mathematical processes were defined and corrected: new possible ways of implementation and the organization of the tested pedagogical strategy in frames of secondary schools curriculum modernization were established.

\section{RESULTS}

\section{The Main Idea of the Technology}

Let us proceed to the description of the meta-subject expertise development technology elaborated for secondary school pupils of $5^{\text {th }}$ grades. The key concept of 'meta-subject expertise development' involved correspondence of technological features of the educational process in mathematics to the main conditions (integration and subjectivity) and multidimensional planning by secondary school students of $5^{\text {th }}$ grades.

The article contains reasonable details of the technology, such as the structure and aims of educational processes among pupils for further development of their meta-subject expertise in mathematics. The technology is implemented due to compliance with new educational standards and in accordance with the mathematical education concept with the help of the unified programmes and approaches to the organization of cognitive activities among pupils of secondary schools.

The main idea of the meta-subject expertise development technology was to consequently implement the systematical, activity-oriented, expertise and meta-subject approaches from the subject-oriented point of view among pupils of $5^{\text {th }}$ grades of the gymnasium. The idea arose from the necessity to renovate the aim, technology, concepts and relevant aspects of the mathematical education due to social demands and the federal education standards of general education. 


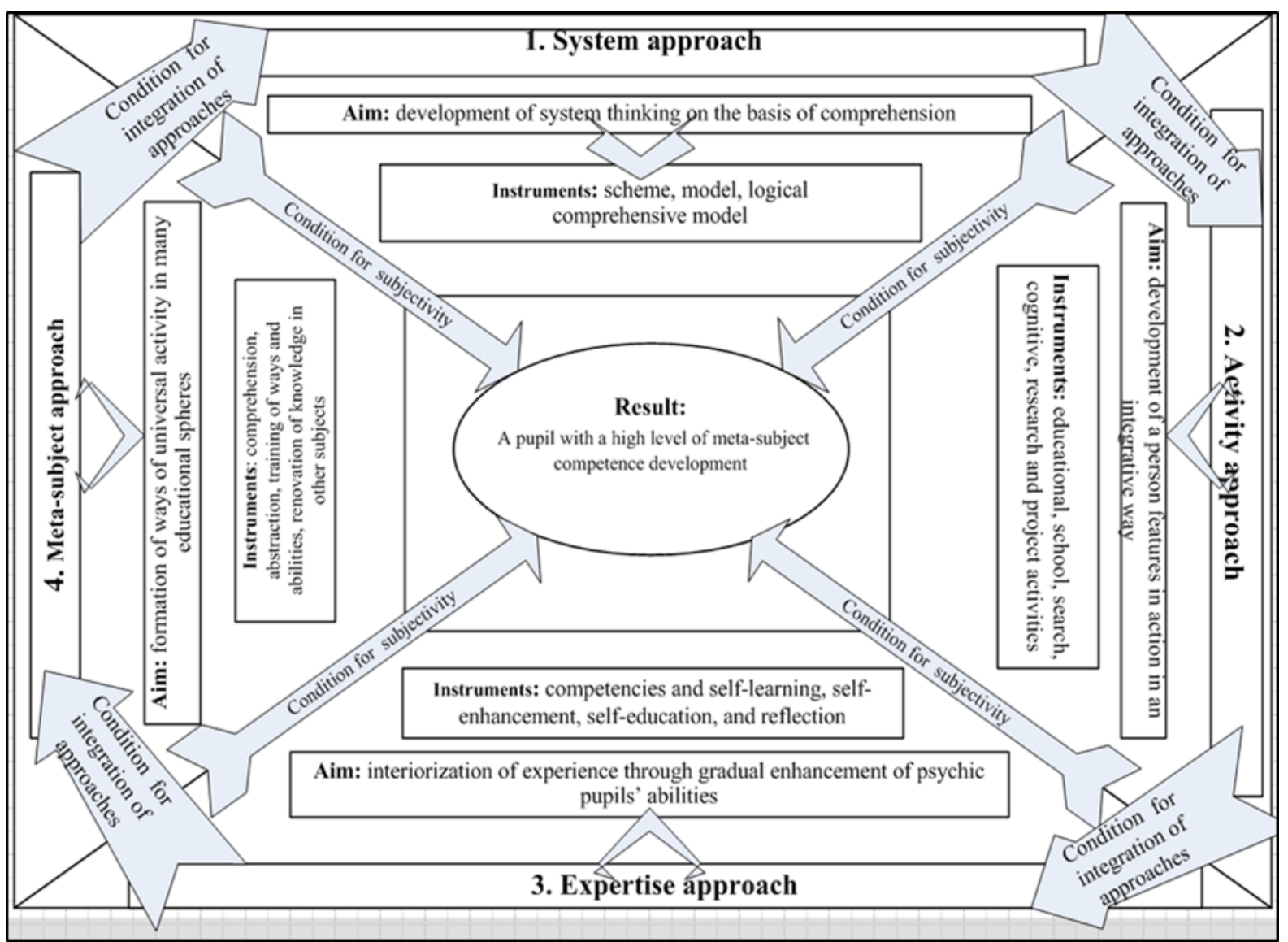

Figure 1. The main conditions of the meta-subject expertise development technology implementation

\section{The Conditions of the Technology Implementation}

The technology was aimed at the consideration of the patterns and features of meta-subject expertise development in educational and the cognitive activity of pupils as subjects of their own cognitive processes. From this point of view, the most effective conditions were created by combined implementation of the system, activityoriented, expertise and meta-subject approaches in the teaching of mathematics as well as with the subject-oriented one in order to achieve a general effect of an integral personal feature - the expertise of a meta-subject character.

Provision of the conditions mentioned above (integration of the approaches and subjectivity) served as the basis for meta-subject technologies implementation. This led to enhancement of the pupils' personal features in educational, cognitive and research activities mainly as subjects of the performed actions defining unified ways of processing and application of the gained knowledge in any educational sphere and social situations. Provision of such conditions is introduced in Figure 1.

Figure 1 illustrates the result, conditions for subjectivity and integration of the approaches in meta-subject expertise development technology. The aim of the activity approach is to develop system thinking on the basis of comprehension among pupils for further development of their meta-subject expertise in mathematics. Instruments are schemes, models and logical comprehensive models. The aim of the system approach is to develop person features in action in an integrative way. Instruments are educational, school, search, cognitive, research and project activities. The aim of the expertise approach is to interiorize experience through gradual enhancement of psychic pupils' abilities. Instruments are competencies and self-learning, self-enhancement, self-education, and reflection. The aim of the meta-subject approach is to form ways of universal activity in many educational spheres. Instruments are comprehension, abstraction, training of ways and abilities, renovation of knowledge in other subjects.

\section{The Technology and the Features of the Technology Implementation}

After implementation of the multidimensional planning theory of V.E. Steinberg, the meta-subject expertise development theory among pupils of $5^{\text {th }}$ grades was proposed. The necessity to elaborate such an approach is 


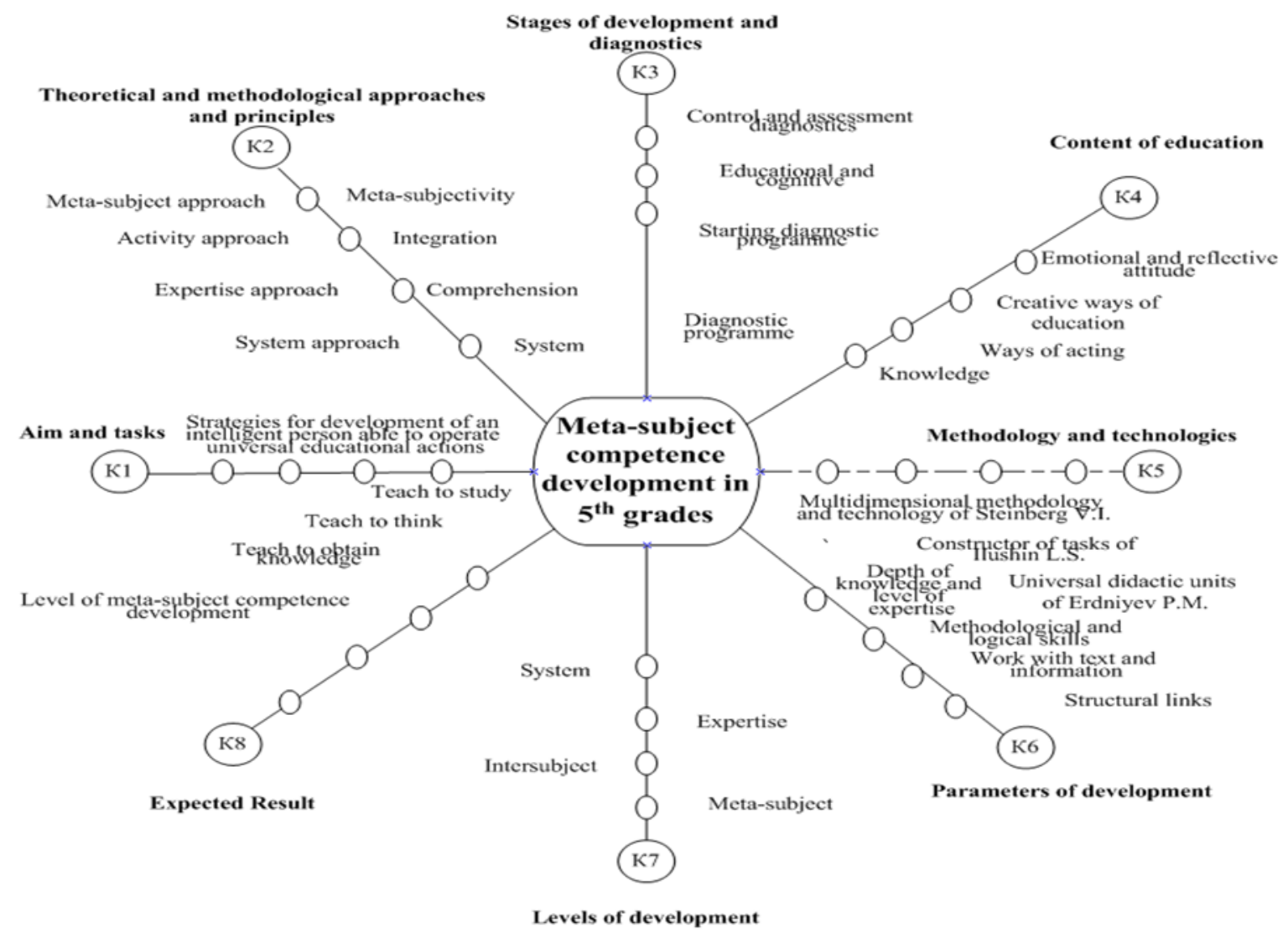

Figure 2. The technological peculiarities of meta-subject expertise development at lessons of mathematics among pupils of $5^{\text {th }}$ grades

explained by the complexity of the educational process aimed at the person with a formed own attitude towards activity and with the appropriate level of meta-subject expertise. In the meta-subject expertise development technology, there are eight main structural elements which should be followed during the organization and planning of the educational process in mathematics (Steinberg \& Khuziakhmetov, 2016). The details are introduced on Figure 2.

Figure 2 shows the stages of the meta-subject expertise development technology starting from defining the aims and tasks (K1 the aim - strategies for development of an intelligent person able to operate universal educational actions; tasks - teach to study, to think, to obtain knowledge), theoretical and methodological principles (K2 systematical, integral, comprehensive, meta-subject tenets), the stages of the formation and diagnostic programme (K3 - starting diagnostic, educational and cognitive, control and assessment diagnostics), the content of mathematical education (K4 - knowledge, creative ways of education, emotional and reflective attitude), the methods and technologies (K5 - multidimensional technology of V.E. Steinberg, tasks constructor of L.S. Ilushin, enlargement of didactical units of P.M. Erdniyev), the parameters of development (K6 - depth of knowledge and level of expertise, methodological and logical skills, work with text and information, structural links), levels of development (K7 - elementary, subsystem, system, meta-subject) are characterized (Steinberg \& Khuziakhmetov, 2016; Illushin et al., 2005; Erdniyev, 2001). The last stage is introduction of the results (K8).

\section{The Statistical Results of the Technology Implementation}

The results obtained during implementation of the meta-subject expertise development technology were assessed by the experts of Gymnasium № 64 (Ufa city) and Gymnasium № 6 (Kazan city) and the educational staff of universities at the beginning and the end of the research. The combined expert group assessment let us analyze the lessons according to the criteria of their efficiency in pupils' meta-subject expertise and unified educational actions development. The totals of meta-subject expertise levels are introduced at Table $\mathbf{1}$. 
Table 1. Levels of meta-subject expertise development among pupils of $5^{\text {th }}$ grades in the control and experimental groups according to the expert assessment method (stating and developing experiments)

\begin{tabular}{lccccccccc}
\hline \multirow{2}{*}{ Level } & \multicolumn{4}{c}{ Control group } & \multicolumn{3}{c}{ Experimental group } \\
\cline { 2 - 10 } & \multicolumn{2}{c}{ Stating experiment } & \multicolumn{2}{c}{$\begin{array}{c}\text { Developing } \\
\text { experiment }\end{array}$} & \multicolumn{2}{c}{$\begin{array}{c}\text { Stating } \\
\text { experiment }\end{array}$} & $\begin{array}{c}\text { Developing } \\
\text { experiment }\end{array}$ \\
\hline & Total-30 & $\%$ & Total-30 & $\%$ & Total-29 & $\%$ & Total-29 & $\%$ \\
\hline System & 16 & 53,3 & 14 & 46,7 & 15 & 51,7 & 10 & 34,5 \\
\hline Expertise & 10 & 33,3 & 11 & 36,7 & 9 & 31,1 & 12 & 41,4 \\
\hline Intersubject & 4 & 13,4 & 4 & 13,3 & 5 & 17,2 & 4 & 13,8 \\
\hline Meta-subject & 0 & 0 & 1 & 3,3 & 0 & 0,00 & 3 & 10,3 \\
\hline
\end{tabular}

Table 1 illustrates that control and experimental groups had almost identical results of meta-subject expertise development on the system level at the beginning of the experiment (control group - 53,3\%, experimental group $51,7 \%)$. Other categories of $5^{\text {th }}$ graders were also identified: $33.3 \%$ of pupils in the control group and $31.1 \%$ of pupils in the experimental group showed an expertise level of meta-subject expertise development, $13,4 \%$ and $17,2 \%-$ an intersubject level and no one had a meta-subject level. At the end of developing experiment it was found that $34,5 \%$ of diagnosed pupils in the experimental group and $46,7 \%$ in the control group had a system level (equal to the low level of meta-subject expertise development), $41,4 \%$ and $36,7 \%$ had an expertise level, $13,8 \%$ and $13,3 \%$ of pupils an intersubject level, $10,3 \%$ and 3,3\% - a meta-subject level. The best results were established in 10,3\% of cases where pupils gave meaningful answers to the questions and demonstrated their own meta-subject expertise.

The statistical analysis of the data significance according to the expert assessment methods showed that before implementation of the technology the pupils had the same levels of meta-subject expertise development, and after application of the technology we defined clear statistically significant differences in the experimental group.

In general, the studies of the efficiency of the meta-subject expertise development technology among pupils of $5^{\text {th }}$ grades of the gymnasium in the mathematical education showed that the first testing of pupils' knowledge was conducted according to the traditional knowledge-oriented technology and their meta-subject expertise level according to the analysis was quite low. The pupils of the experimental group were completely unprepared for the education oriented to meta-subjectivity. Therefore, the teacher had to explain them more thoroughly advantages of meta-subjectivity and meta-subject expertise development. Pupils played meta-subject games developing skills of application knowledge from other spheres. The key methodology of meta-subject expertise development was based on 'Multidimensional technology of V.E. Steinberg', 'Tasks constructor of L.S. Ilushin,' 'Enlargement of didactical units of P.M. Erdniyev' (Erdniyev, 2001; Illushin et al., 2005; Steinberg \& Khuziakhmetov, 2016).

Thus, implementation of meta-subject expertise development technology among pupils of $5^{\text {th }}$ grades let achieve productive results in the continuous personal development of the pupil who is able to adapt to educational conditions, proportionally responsive to changes in the structure and content of educational processes and ready for continuous self-development. The quantitative results were processed from a statistical point of view and led to defining of significant changes in the experimental group before and after implementation of the technology. Moreover, this technique can be recommended for application in other educational spheres.

\section{DISCUSSIONS}

After implementation of the meta-subject expertise development technology reflection regarding main features of a mathematical education process on the meta-subject level was conducted. A pupil's own subjective opinion of activity is the regular integral feature which has to be shown on the system, expertise, intersubject and meta-subject levels. The constructive role of this feature is connected with the implementation of the technology taking into the consideration the psychological and age characteristics of pupils in $5^{\text {th }}$ grades.

The next main feature is the step-by-step training of knowledge application with the help of the system, expertise, intersubject and meta-subject approaches. This means that, for instance, when dealing with figures in view of the system approach a general policy, its main elements and connective parts are defined. On the expertise level, universal educational actions are trained which further are used performing different activities and applying acquired knowledge and skills on the intersubject level. On the meta-subject level, we deal with integration with another subject, social and domestic, every day and even professional standards (for example, when we need to count the necessary quantity of wallpapers or tiles during decoration works in order not to buy excessive or unnecessary construction material).

The main conclusion to be made after the conducted research is as follows: meta-subject expertise development among pupils of $5^{\text {th }}$ grades is efficient when strict compliance with the elaborated technology is considered to be the aim of the scientific, educational process. 
Along with success of the elaborated meta-subject expertise development technology, some difficulties of its implementation have to be noted. The first problem is that though there is a lot of explanations for the term 'expertise,' there is also a necessity to follow the theoretical and methodological approaches. It hindered comprehension and identification of possible ways of improvement of the pedagogical process aimed at metasubject expertise development among pupils of secondary schools. The consideration of the approaches as well as they're the organization from the system to meta-subject levels is a solution to this problem.

Another difficulty was the analysis of the technology implementation, as it had to be carried out taking into account the following: firstly, the data characterizing expertise development were studied on the various levels of the acquisition; secondly, the meta-subject development feature lies in the fact that it is an integral process where all components of the process are formed simultaneously; thirdly, the experimental work is aimed only at the possibility of formation of the elements of meta-subject expertise development that means strict compliance with the defined aim. Moreover, the excessive resources hindered defining whether the chosen methodology corresponded to the results. These problems were solved by the criteria, and parameter analysis of each component of meta-subject expertise conducted not individually but using the common parameter of meta-subject expertise development taking into the consideration the expert assessment data.

During the implementation of the meta-subject expertise development technology, it was rather difficult to change one-dimensional thinking. For example, a pupil can easily provide detailed information on a familiar subject on mathematics in the oral or written form, but when we change the shape and use the multidimensional system of keywords on a graphic basis, we need to apply our logical abilities and coordinate our knowledge background. Increasing demands of logical skills, conceptualization, and depth of the knowledge acquisition make meta-subject expertize development more complicated; therefore, a teacher has to pay more attention not only to correction works but in the greater degree to the prevention of possible complications.

The defined difficulties and successful results of the technology of meta-subject expertise development can be continued and are likely to bring significant results after being applied in the pre-school and school education. Furthermore, we are quite sure that the advanced technology can be implemented in other educational spheres.

\section{CONCLUSION}

After the analysis of different points of view concerning continuous education with the help of mathematical devices aimed at the achievement of high educational results on the meta-subject level the technology of metasubject expertise development among pupils was elaborated and further implemented. The approbation of the content and forms of teaching of $5^{\text {th }}$ grades pupils conducted for mathematical education enhancement let us build a technological chain of an educational precise process taking into account features of pupil's meta-subject expertise development. The stages of the technology implementation were proposed consisting of the following structural components: the aims and tasks, the theoretical and methodological principles, the formation stages and diagnostic tests, the content of education, the methodologies and technologies, the criteria of development, the expected result. Experimental teaching using the meta-subject expertise development technology formed the methodological approaches to the mathematical education in secondary schools regulating personal pupil's progress who is ready for continuous self-development. Implementation of the technology enhances pupils' results in the acquisition of the meta-subject skills as well as their own elaboration of educational strategies. Thus, the proposed technique of meta-subject expertise development in $5^{\text {th }}$ grades with the help of the mathematical instruments is aimed not only at continuous development of mathematical education but also at keeping pupils permanently interested in an educational mathematical process training self-learning and reflection.

\section{RECOMMENDATIONS}

The article is rather significant for the teachers applying the intersubject and meta-subject approaches to mathematical education, for teachers of extracurricular courses who pursue to enhance not only their own methodological skills but also their pupils' development and the acquisition of mathematical knowledge. Moreover, the introduced technological features of meta-subject expertise development can be implemented in other educational spheres.

Possible enhancement of the proposed meta-subject development technology and features of its implementation can be carried out taking into account the aspects connected with remote education, namely: remote support of pupils' activity during an education process and distribution to several educational establishments with the interaction of teachers, the technology developers, and pupils. 


\section{ACKNOWLEDGEMENT}

The work is performed according to the Russian Government Program of Competitive Growth of Kazan Federal University.

\section{REFERENCES}

Asadullin, R. M. (2009). Reform priorities of teacher education. Retrieved from http://oprb.ru/data/partner/8/message/7Gu7J871_2840.pdf.

Borenstein, M., Hedges, L. V., Higgins, J. P., \& Rothstein, H. R. (2009). Introduction to Meta-Analysis. London: John Wiley \& Sons. https:/ / doi.org/10.1002/9780470743386

Borenstein, M., Hedges, L. V., Higgins, J. P., \& Rothstein, H. R. (2010). A basic introduction to fixed-effect and random-effects models for meta-analysis. Research synthesis methods, 1(2), 97-111. https://doi.org/10.1002/jrsm.12

Brock, L. L., Rimm-Kaufman, S. E., \& Wanless, S. B. (2014). Delay of gratification in first grade: The role of instructional context. Learning and Individual Differences, 29, 81-88. https:/ / doi.org/10.1016/j.lindif.2013.10.012

Carr, M., \& Borkowski, J. G. (1989). Attributional training and the generalization of reading strategies with underachieving children. Learning and Individual Differences, 1(3), 327-341. https://doi.org/10.1016/10416080(89)90015-0

Chilingaryan, K. P., \& Gorbatenko, R. G. (2014). Competence and competency. Ability and motivation. Language, Individual \& Society. Journal of International Scientific Publications, 8, 40-53.

Cohen, J. S., \& Smerdon, B. A. (2009). Tightening the dropout tourniquet: Easing the transition from middle to high school. Preventing School Failure: Alternative Education for Children and Youth,53(3), 177-184. https:/ / doi.org/10.3200/PSFL.53.3.177-184

Delamare, F. L., \& Winterton, J. (2007). What Is Competence? Human Resource Development International, 8, 27-46.

Duan, Q., Jiao, J., Chen, X., \& Wang, X. (2018). Association between water fluoride and the level of children's intelligence: a dose-response meta-analysis. Public Health, 154, 87-97. https:// doi.org/10.1016/j.puhe.2017.08.013

Erdniyev, O. P. (2001) Genesis of Methodical System of Enlargement of Didactic Unities (EDU) in the Works of the Academician Erdniyev P. M. Bulletin of the Kalmyk Institute of Social, Economic, and Legal Studies, 2, 172-185.

Gein, A. G., \& Nekrasov, V. P. (2013). Metacognitive Invariants as Psychological-Pedagogical Factors of Training. Universal Journal of Educational Research, 1(2), 128-132.

Gorev, P. M., \& Masalimova, A. R. (2017). Development of Meta-subject Competencies of the 7-9 Grades Basic School Students through the Implementation of Interdisciplinary Mathematical Courses. Eurasia Journal of Mathematics, Science and Technology Education, 13(7), 3919-3933.

Gorev, P. M., Masalimova, A. R., Mukhametzyanova, F. S., \& Makarova, E. V. (2017). Developing Creativity of Schoolchildren through the Course "Developmental Mathematics." Eurasia Journal of Mathematics, Science and Technology Education, 13(6), 1799-1815. https:/ / doi.org/10.12973/eurasia.2017.00698a

Guruzhapov, V. A. (2012). The problem of interdisciplinary competence assessment of the subjects. Psychological science and education, 3, 64-66.

Hu, B. Y., Ren, J., Lo, C. C., Roberts, S. K., Yang, Y., \& Vong, K. I. (2018). Chinese kindergarten teachers' use of instructional support strategies during whole-group language lessons. Teaching and Teacher Education, 70, 34-46. https:/ / doi.org/10.1016/j.tate.2017.10.016

Illushin, L., Hufton, N., Willis, W., \& Elliott, J. (2005). Motivation, engagement, and educational performance: International perspectives on the contexts for learning. London: Springer.

Khutorskoy, A. V. (2003). Didactic heuristics: Theory and technology of creative learning. Moscow: AST.

Khutorskoy, A. V., \& Kraevskiy, V. V. (2008). Meta-subject functions of educational competencies. Teaching basics: Didactic studies, 5, 140-144.

Khuziakhmetov, A. N., \& Sytina, N.S. (2016). Educational Process Navigator as Means of Creation of Individual Educational Path of a Student. International Journal of Environmental and Science Education, 11(9), 2255-2264.

Khuziakhmetova, A. N., \& Naumova, M. V. (2016). Diagnostics of Pupils' Meta-Subject Competence during Lessons on Mathematics in Secondary Schools. International Journal of Environmental and Science Education, 11(9), 2333-2342. 
Konovko, O. V. (2012). The possibilities of modern mathematical education in school. Teacher education in the Altai, $1,377-380$

Köymen, B., \& Tomasello, M. (2018). Children's meta-talk in their collaborative decision making with peers. Journal of Experimental Child Psychology, 166, 549-566. https:/ / doi.org/10.1016/j.jecp.2017.09.018

Kraevskiy, V. V., \& Khutorskoy, A. V. (2003). Subject and meta-subject in educational standards. Pedagogy, 2, 3-10.

Lebedev, O. E. (2004). Competence approach in education. School of technology, 5, 3-12.

Leontiev, A. N. (1956). A child's mental development. Moscow: Academia.

Lerner, I. Y. (2003). Didactic bases of teaching methods. Moscow: Pedagogy.

Masalimova, A. R. (2017). Development of Meta-subject Competencies of the 7-9 Grades Basic School Students through the Implementation of Interdisciplinary Mathematical Courses. EURASIA Journal of Mathematics, Science and Technology Education, 13(7), 3919-3933.

Miller, P. H. (1994). Individual differences in children's strategic behaviors: Utilization deficiencies. Learning and Individual Differences, 6(3), 285-307. https:/ / doi.org/10.1016/1041-6080(94)90019-1

Novikov, A. M. (2010). The Foundation of pedagogy. Moscow: Evges.

Osgood, C. E., \& Tannenbaum, P. H. (1955). The principle of congruity in the prediction of attitude change. Psychological Review, 62,42-55. https://doi.org/10.1037/h0048153

Praet, M., \& Desoete, A. (2014). Enhancing young children's arithmetic skills through non-intensive, computerised kindergarten interventions: A randomised controlled study. Teaching and Teacher Education, 39, 56-65. https:// doi.org/10.1016/j.tate.2013.12.003

Quail, A., \& Smyth, E. (2014). Multigrade teaching and age composition of the class: The influence on academic and social outcomes among students. Teaching and Teacher Education, 43, 80-90. https:/ / doi.org/10.1016/j.tate.2014.06.004

Rubinstein, M. M. (1913). Essay on educational psychology in the context of General pedagogy. Moscow: AST.

Sanderse, W., Walker, D. I., \& Jones, C. (2015) Developing the whole child in an age of academic measurement: Can this be done according to U.K. teachers? Teaching and Teacher Education, 47, 195-203. https:/ / doi.org/10.1016/j.tate.2015.01.010

Semenov, A. L. \& Atasyan, S. L. (2014). Formation of mathematical competence in primary school. Science and school, $5,7-12$.

Sneed, T. G., Carlson, J. S., \& Little, T. D. (1994). The relationship of teacher and parent ratings of academically related personality traits to academic performance in elementary age students. Learning and Individual Differences, 6(1), 37-64. https:/ / doi.org/10.1016/1041-6080(94)90014-0

Sopegina, V. T., Chapaev, N. K., \& Simonova, M. V. (2016). Integration of Pedagogical and Technological Knowledge in Forming Meta-Competencies of a Modern Worker. International Journal of Environmental $\mathcal{E}$ Science Education, 11(15), 216-225.

Steinberg, V. E., \& Khuziakhmetov, A. N. (2016). Logical-Semantic Visual Navigators-Aids for Teachers. International Journal of Environmental and Science Education, 11(8), 1877-1887.

Testov, V. A. (2014). Problems of realization of the concept of development of mathematical education. Actual problems of teaching in mathematics, 2, 152-154.

The concept of development of mathematical education in the Russian Federation. (2013). The Russian newspaper. Retrieved from http://www.rg.ru/2013/12/27/matematika-sitedok.html

Verbitskiy, A. A., \& Ermakova, O. B. (2009). School contextual learning as a model of realization of competence approach in General education. Innovative programs and projects in education, 4, 22-25.

Voltmer, K., \& Salisch, M. V. (2017). Three meta-analyses of children's emotion knowledge and their school success. Learning and Individual Differences, 59, 107-118. https:/ / doi.org/10.1016/j.lindif.2017.08.006

Vygotskiy, L. S. (1999). Educational psychology. Moscow: Pedagogika Press.

Yakushev, M. V. (2013). Concerning a possible approach to students' learning outcomes assessment. European journal of Social Sciences, 7, 105-106.

\section{http://www.ejmste.com}

